\title{
Sexuality and Its Preferences: between Binary and Plural Logic
}

\author{
Philipp Tagirov \\ Department of Social Philosophy \\ Peoples' Friendship University of Russia \\ Miklukho-Maklay str., 10/2, Moscow, Russia, 117198 \\ E-mail: tagirov_fv@pfur.ru
}

\begin{abstract}
The article analyzes a possibility of sex-identity built outside binary oppositions that are structural foundation for both our culture and our thinking. It also studies the problematic overcoming of the binarity without forming a new binary opposition. The author questions the limits and possibilities of humanism within the binary typization and conceptualization of a subject, as well.
\end{abstract}

Keywords—binarity; discourse; eros; gender; humanism; identity; plurality; sex; sexuality

\section{INTRODUCTION}

When we see a woman (or a man) in the beloved does our beloved stay with us? Or is somewhat individual, unique, exclusive obscured by what is typical and common? What happens if we see a beloved woman (or a beloved man) in a beloved? Do we not see what's uncommon but one of a row, an exclusion from some similar type? However, how is this exclusion defined? Whether we take femininity/masculinity as attributes of the unique or as a substantial root from which there grows an individuality that mostly remains "the same as" any other object of a kind? In the first case, the uniqueness puts on the qualities of sex like clothes. In the second one exactly what we believe to be individual and unique are clothes, something external, mirage, and a shell behind which the same, and the same, once again, reveals itself.

Does even less uniqueness remain when we speak not about love, object of which is always exclusive, one of a kind, but primarily about sexuality, object of which is generally typical?

And when it's not the other but myself I define by type, through some group identity do I find exactly my self or do I lose it (maybe in something like existentialist indefinitepersonal "man")? On one hand, how can one speak or even think of oneself without self-identification? On the other hand, what remains in me from myself when this or that identity starts dominating over other ones?

Is it possible that there could be no "me" preceding my identity? However, I (what differs me from any other) might not be expressed through any identity but rather through a configuration of my identities or even through an individual dynamics of identifying correspondences in this configuration.

\section{IN THE TRAP OF GENDER BINARITY}

In the first binarity of the sexual, the one I love is reduced to one of the polarities in opposition "man" "woman". "Man" is prescribed to possess certain attributes and play certain roles that make him a "man" differentiating him from a "woman". The similar mechanism constitutes a "woman". We realize our love for a "woman" (or for a "man") against the background of preset expectations, and we foresee an object of our love as a possessor of these attributes and a performer of these roles.

I also discover myself through being "man" or "woman". As a "man" or "woman", I generally prescribed to be a subject of a particular desire.

What would deliver the lover and the loved from being reduced to "general type" in this preset binarity? It could be an assumption about social and cultural basis of prescribed attributes and historical temporality of roles. It could also be an assumption that desire can be oriented in some other way without the subject of this desire risks being enlisted in a new general category like biological degenerate, moral invalid, criminal, lunatic, etc.

Is it an overcome of the binarity "man - woman"? In any case, it is an overcome of strict and uncontested designation based on this binarity. Does it deliver the individual from the toils of the typical? Hardly, because the subject of an "atypical" desire finds himself (or herself) in a specific category that marks this desire as exactly "typical". The opposition of "typically atypical" and "typically typical" gives birth to the second binarity that is the binarity "homosexuality - heterosexuality".

Contemporary scientific theory has rid itself of the concept of "degeneration" which was used in the past to discoursively localize subjects of "atypical" desire; nowadays, the concept of "perversion" is being replaced by more neutral term "paraphilia". But like "perversion", the concept of "paraphilia", succeeding it, includes a rather broad list of various forms of "deviating" desire. The question of paraphilic status of homosexuality is interesting not only because of its presumed axiological neutrality but 
also because the very questioning today means different things than before. With straight heterosexual discourse overwhelmingly dominating the defining homosexuality as paraphilia or perversion provides the basis for eliminating of this phenomenon as wrong and impermissible or at any rate its marginalization, tabooing, concealing and veiling. In the case of public, scientific and even juridical coexistence of heterosexual and homosexual discourses, the recognition of homosexuality (legitimized in many ways and in many places) as paraphilia is not aiming at its delegitimation but could surprisingly lead us to revising status of other "paraphilias", possibly making them demarginalized. The contemporary comparative studies of homosexuality and paraphilias, for example, performed by James M. Cantor, points at how homosexuality differs from main paraphilias or at least its specific place among them [1. P. 237]. This is if we define paraphilia as a sexual desire and a sexual behavior that is atypical for a sex than homosexuality belongs to paraphilias, suggests J. Cantor. But if we say that paraphilia is sexuality atypical for a specie, then, homosexuality is not paraphilic. According to empirical data and comparing a number of correlates between these phenomena (like brain organization, fraternal birth order, handedness and others), J. Cantor concludes homosexuality and paraphilias have different etiology. However, he accepts that many "paraphilias" could also have dissimilar origin.

The problematic status of the binarity "heterosexual / homosexual" is also revealed by the fact that, accordingly to many researchers, the very concept of homosexuality is not homogeneous for there is no some universal homosexuality, and we should first of all distinguish male and female homosexuality. They notice, for instance, that statistically among men, homosexual individuals are met much more often than bisexual while among women we have the reverse situation. Besides, men generally appear to have more paraphilias than women with an exception of masochistic behavior (in its broad meaning) of which the women show comparably often. Scientists admit that within current state of scientific knowledge we have no reason to claim that there are the same causes for homosexuality of men and one of women [1. P. 239]. Thereby the question arises: does such thing as homosexuality as such exist? Does this concept indeed includes phenomena put together essentially and not just in accordance to surficial formal criterion? Instead of binarity, we'll get leastways the triad of "heterosexual / homosexual man / homosexual woman" which can evolve into four-membered structure if we ask ourselves whether we mingle man and woman into one assuming now heterosexuality is the same for them. It's not just anatomy and physiological processes but experience as well that cannot be transferred to a person of the other sex problematizes the idea of mingling male and female heterosexuality into one universal heterosexuality.

As a rule, we presume homosexuality and heterosexuality differ in accordance to the difference between their preferable objects of desire: in the first case, it's a desire towards the similar, and, in the second one, it's directed to the different. However, do these two concepts really differ by preferable objects of desire? Our common sense, our experience and finally the very etymology and semantics of these words speak exactly of this point. But aren't these concepts the expression of an existing understanding of certain structures of relations between individuals? Perhaps we should distinguish them not by preferable, but by excluded object? Should we probably start with a notion that, for instance, person A doesn't prefer objects of a particular sex B - similar or different from his or her own - but rather excludes any objects non-B? Wouldn't a male "homosexual", for example, appear not as a one whose desire is directed to men instead of women (as we could think from the point of how the first binarity designates) but rather a one whose desire accepting men as its objects excludes, avoids women?

When studying the cause of inner psychological hostility towards the same-sexual orientation of desire, some theorists and Judith Butler in particular pay their attention to hypothetical presence of homoerotic tendencies of any child [2. P. 59-60]. However, the "matrix of compulsory heterosexuality" does not allow these tendencies to develop in most cases, moreover an individual being homosexual himself or herself is compelled to deny this part of self, fight it, and avoid even an assumption of its existence. Hypothetically, this inner struggle gradually nurtures a radical rejection of what is discarded, and a person refuses to tolerate it within him- or herself as well as in any other. Finally, it reproduces the "compulsory matrix" and forms the similar antagonism among the following generation. J. Butler notes that, according to Sigmund Freud, our Ego assimilates certain individual structures of the beloved person that we lost. This should be further explained. While our beloved is by our side, while the communication with him (or her) is available we do not need to interiorize the one we love because we can always address him (or her) as an externalized other in the situation "face to face". Moreover, in the presence of the one we love, we could afford to differ in a rather fundamental way, manifesting our otherness and autonomy in a love agon. But while parting and suffering from the lack of our dear person, we begin to look around "as if" through his (or her) eyes. We tend to notice what he would notice, appreciate what he would appreciate and condemn what he'd condemn. When parting is over we discover our beloved as an externalized other again and the opportunity of agon resumes. The death of the one we love irreversibly terminates the possibility of reestablishment of his external subjectness; our beloved that remains is solely our beloved in us. We are our beloved people that we lost.

With the assimilation of the personality structures of the one we love, we also assimilate the specifics of his/her desire. It is widely accepted that, according to Freud, the main factor influencing the forming of our desire is the "Oedipus complex" that integrates (for boys) adoration for the father and a wish to mime him, mime his desire but it also includes the prohibition for the object of his desire. J. Butler supposes that, from the point of its significance for the forming Ego of a child, the incest taboo (that is the prohibition of love for mother) backs down before the love for the father which is even more prohibited by the dominating heterosexual matrix. Why does the son mimic his father's desire? Why does he try to reprise his father within himself? The answer is that his 
father (the object of his love and adoration) almost from the very beginning occurs to be unreachable for his love, in other words - lost [2. P. 58]. A similar situation (in its mirror form) is generally typical for girls. For Freud, as well as for some other theorists like Havelock Ellis, for instance, the original potential of an individual is bisexual. The fact that desire subsequently becomes fixed on one of sexes (predominantly on the opposite one) is determined by a complex set of agents including those of biographic, social and cultural order [3. P. 224]. But if so, shouldn't we say that our desire is not given a prescribed object but rather prevented from seeking anything else than objects of a certain type? Shouldn't we suppose that the prohibition of desire that isn't channeled by the sex of its object turns out to be much more severe than the prohibition of same-sexual desire?

In that case, factors influencing composition of included and excluded objects of desire will be considered differently by constructivist and essentialist theories (that is by discourses of desubstantialized and substantialized desire [4]). Still, even those who study our sex as rooted in its corporeality (before any social and political contexts) admit that genetic sex of a person may not match the anatomic one and wherein result in both masculine and feminine identity [5. P. 151.]. Will the claim of such binarities as "man / woman" or "heterosexual / homosexual" for universality remain convincing?

Actual presence of same-sexual affection occurred to be a challenge to heterosexual model [6]. The demand for recognition of human bisexuality rises as a much more radical challenge - a challenge to monosexuality, both heterosexual and homosexual. If bisexuality could help us to overcome the second binarity we would very soon find ourselves imprisoned in the cage of the third binarity captured inside the opposition of "bisexuality / monosexuality". Some researchers of bisexuality believe that pro-homosexual discourse seeking for legitimation creates a very narrow conservative identity that essentially doesn't differ from traditional heterosexual pattern [7. P. 298], while bisexuality could become a real "deconstructing" breakthrough, the liberation of gender identity, bisexuality could become a "postmodernism in the flesh" [3. P. 218].

\section{THE QUEEREST OF THE QUEER OR THE CHALLENGE OF BISEXUAL IDENTITY}

One of the common arguments against bisexuality comes from weakly conceptualized undistinguishing usage of the words "monosexuality" and "monogamy". But does monosexuality really guarantee monogamous relations, at least in a form of serial monogamy? And does bisexuality necessarily suggests polygamy? [7. P. 304] As well as heterosexual, homosexual or any other sexual identity bisexuality marks the field for the possible conceptualization of our desire but in no way depicts moral characteristics of behavior patterns of a subject.

On the background of numerous manifestations of homosexual kind - whether they are shocking and outrageous or proving the pride and determination of a person committing a coming-out; whether they are of political or aesthetical nature - there is a noticeable innoticeability, obscurity and silence about bisexuality. The similar question was once proposed about the "invisible" women [8. P. 78-88], about the "invisible" gays; doesn't it mean that in case of wide recognition of the "invisible" bisexuals other identities that remain "invisible" for now will begin their fight for legitimacy? Some authors state that "biphobia" a subject of bisexual desire suffers appears to be much harsher than "homophobia" for homosexual subject because homosexuals "at least do not question monosexual certainties" [9. P. 21]. It's not only the heterosexual majority but also advocates of homosexual discourse that often disclaim the very fact that bisexuality exists for the latter "destabilizes not just sexuality, but sex" [7. P. 301], and "sex" is highly important for homosexual identity this discourse needs as a footing to build its political strategy. Bisexuality threatens to be dismantling for the essentialistic basement of homosexual identity: the "same-sexual destiny" would be replaced by "same-sexual choice". When the proponents of both monosexual models meet actual bisexuality that they cannot deny (but isn't it easier to question bisexuality on the level of sex?), they tend to prefer to position it as a sort of transitional, interim phenomenon between heterosexuality and homosexuality or between homosexuality and heterosexuality.

In the 90s, the "queer theory" was proposed as a theoretical formulation of a protest against the compulsiveness of any model of sexuality even the one statistically dominating. The original impulse of queer theory and queer identity, as some researchers like David M. Halperin define it, is supposed to be adogmatic, critical and establishing broad place for possible experimentations [10. P. 111]. It is essentially that the queerness of the queer doesn't imply any particular identity, what's more the queerness demands refusing of self-identification by the means of any certain pattern; it is the identity of individuals who want to "label themselves with nonlabel" [3. P. 214]. However, all revolutions indeed contain a counterrevolutionary potential and, at a certain moment, are doomed to be betrayed by those forces that used to be their main engine as soon as they get over their submissive, depraved status and obtain speech, rights, power and become political subjects that couldn't be ignored anymore. And instead of promised liberation, there comes a restoration of old order of power in a new form. Having initially put itself as a protest identity "beyond any categories", queer identity more and more often gives in to the temptation of reification. Queer becomes not queer enough. Calling for identity that evades any gender categorizations, queer discourse raises a question about possibility or even necessity of deconstruction of "sex", in doing this it's largely based on Michel Foucault turning "sex" from natural into discoursive reality [11]. According to Foucault [12. P. 12], control over sexuality is being established not as much through the repression and silencing as through the "putting into discourse". But putting into discourse also allows forming some particular identity and gaining certain subjectness, even if it is suppressed and deprived. Such reification has already reached individuals who define themselves by same-sexual desire thus constituting "homosexual minority" and creating 
"homosexual identity". Admitting that becoming any particular identity queer identity finds itself in contradiction with its own principles bisexual discourse however risks following the path of homosexual one when proposing to use the mechanism of "bringing into discourse" so that it could overcome its "invisibility" too [3. P. 226]. But shouldn't we see in this, according to Foucault's logic, not only obtaining of the subjectness but also turning oneself into an object of power relations built in and in accordance to current discourse, into an object that from now on would be unable to evade being classified, controlled, depicted and regulated?

Standing for their own identity the participants of bisexual discourse refuse to agree with the definition of bisexuality as a transitional form. Furthermore, they don't accept the idea of bisexuality as merely a sum of "heterosexual" or "homosexual" acts, relations or desires [9. P. 20]. Yet, bisexual models differ from the point of behavior as well as from the point of self-identification. So, according to behavior we can, for an instance, distinguish following types of bisexuality [9. P. 13]: sequential (different objects of desire does not form a conflict for they belong to different temporal periods; and also there is no contradiction with the model of serial monogamy), concurrent (two or more different lines of relations coexist in the same period of time; and here is a contradiction with monogamy pattern) and simultaneous (actually bisexual experience in a single moment of intimacy). D. Halperin counts up to 13 kinds of bisexuality [13. P. 452]. By inner organization researchers differentiate "conflict" and "flexibility" models of bisexuality [9. P. 19]. The conflict model assumes the fundamental difference of sexes, and, as a result, the irremovable confrontation between desires addressed men and women exists. Bisexual identity of this kind can be 1) transitory (situational or experimental), 2) transitional (for example, from heterosexual to homosexual identity) and finally 3) defensive (against, for instance, the fear of assuming one's own homoerotic desire) [9. P. 16-17]. These three types represent so called "pseudobisexual" orientation; the conflict remains in each of them, it can only be suppressed or partially cancelled by "indifferent" ("ambisexual") identity when a subject claims it's the personal qualities but not the gender of a partner that really matters. If there are only two sexes and they constitute a strict opposition than how (otherwise than through indifference) is bisexuality that combines oppositely directed desires ever possible [7. P. 304]? (And if it is possible doesn't this indicate that we should reconsider the degree of how sex as such is fixed?) The "flexibility" model denotes a fundamentally different type of bisexual identity - the one that seems to be a manifestation of the androgynous nature of human being and human desire. Moreover, bisexual desire is often denoted not as a desire addressed (sequentially or concurrently) representatives of different sexes but as a one for another bisexual regardless his or her sex. And so don't we come to an essential question: whether these models represent just different types of bisexuality or different genders at all? Doesn't the very gender disposition begin to shatter? The queer theory in its initial message wasn't a theory of protest of a particular gender (homosexual, for instance) against the oppression from another particular one (heterosexual, for instance) [14. P. 102]: the principle of protest demanded to be homosexual (the queer one) in heterosexual society but (!) to be heterosexual in a society of, let's say, "compulsory homosexuality". How could such protest be even possible if our desire is considered strictly fixed by natural or social mechanisms? Proceeding further in this direction aren't we getting closer to the only solution for the third binarity, binarity of "monosexual / bisexual", that would question not just the basis of bisexuality but also whatever numbered basis for counting and regulating subject's desire? Won't the assuming of the polymorphism of human desire become the mean for liberation from any binarities of sexuality?

\section{POLYSEXUALITY AND HUMANISM OF PLURALITY}

The idea of human polysexuality can be derived, for example, from the nature of gender identity. Does identity exist before it's expressed? And if so, can it be somehow perceived by external observer or even by the very subject of this identity? If a subject tries to speak about his (or her) identity before its expression, doesn't that speech become its discoursive performance? What could he possibly think of his identity? How could he define it before and beyond its expressions? According to J. Butler performative field for gender identity is constituted by the body of a subject and its multiple different effects - that is his corporality [2. P. 185]. But body is not just ontology but also a construct, it directs but it can also be directed.

Couldn't the assumption of human polysexuality lead us to cancellation of "sex" or to its growing diversification [9. P. 20]? If we recognize the original polymorphism of sexual object, wouldn't it get us to an infinite number of sexes that is as useless for us methodologically as a denial of sex at all? Accepting the idea of sociogenic nature of gender essentialism suggests going deeper and seeking hypothetical "protogender" identity [9. P. 18]. Constructivism points out that the number of genders/sexes in our methodology should not be initially taken as two or any other number but exclusively determined by current tasks.

We should probably think of sexuality not as dichotomy but as continuum [14. P.98], where any of its forms potentially transit into adjacent ones and thus there is not a chasm between any "oppositional" elements but multiplicity of transitional forms. These forms are not what are realized in person; they are by what a person (among other ways) realizes himself. Sexuality itself, energy of sex possibly doesn't know its object and only channeled by particular mechanisms in certain contexts - whether it's biological mechanism of reproduction or social mechanism of gender expectations. As P. Berger and T. Luckmann noticed: "Left to himself, man may attach himself sexually to just about any object" [15. P. 202].

While binarity "bisexuality / monosexuality" is actualized in the context of matrimony and its monogamic form, binarity "homosexuality / heterosexuality" has a crucial meaning in regard to the problem of reproductive sexuality. Recreative sexuality (and may be sexuality in 
general?) actually is essentially neither "hetero-", nor "homo-", nor "bisexual".

Sexuality primarily works with imagination and not with the reality. Original reality is naked; it bears no presence of human or humanity. Reality should be additionally thought over, invented, built up to become desirable; it is human fantasy that builds it up. This is true for the moments of intimacy when the other person is inevitably perceived not only in his (or her) uniqueness (and sometimes indifferently to it) but also in some typicness (that is simplified) and augmented, enhanced to something bigger so he could hold the transgressive impulse of eroticism that ultimately addresses the totality of all. The importance of our ability for abstraction and our imagination in the sphere of sexuality is even more obvious in case of dreams (when regardless the lack of actual subjectness of the other and any physiological contact with him sexuality remains and often reveals itself in more liberated forms than in our everyday behavior performance) and also in autoerotic experience. In that experience, the desirable object can be not only of the opposite or the same sex but a sexless inanimate object too and even an indefinite object when in his or her fantasy an autoerotic subject is focused not as much on the external object as on its effect on his or her body.

"Love people, not genitalia" [3. P. 229]. Perhaps this humanistic slogan formulated by bisexual discourse should be extended beyond the boundaries of the binarity "bisexuality / monosexuality". Speculating about the nature of seduction, J. Baudrillard studies the idea that sexes are not two, not four, not some particular number; sexes are countless (probably as many as people?) [16. P. 23-24]. If every person has the unique sex than concepts of "heterosexuality" and "homosexuality" lose any sense as well as the concept of "bisexuality" that, if remain, would still reduce any person to binary typology. "Making love is not just becoming as one, or even two, but becoming as a hundred thousand," - J. Deleuze and F. Guattari state supposing plurality of our desire and of very subject understood as "schizo-subject". "Desiring-machines or the nonhunian sex: not one or even two sexes, but $n$ sexes. Schizoanalysis is the variable analysis of the $n$ sexes in a subject, beyond the anthropomorphic representation that society imposes on this subject, and with which it represents its own sexuality. The schizoanalytic slogan of the desiringrevolution will be first of all: to each its own sexes" [17. P. 296].

However, when we assert the fundamental polysexuality, don't we become one of the elements in the opposition between those who recognize this polysexuality and those who stand for certain sexual identity? On one hand, this binarity seems to be of quite different order than the previous three for here we deal primarily with methodological or ideological binarity that exist "in heads" and not "in bodies". On the other hand, if we assume that every person is originally polysexual, then all previous binarities like the one of "heterosexual / homosexual" are also first of all binarities "in heads".
While analyzing the roots of binary thinking, J. Butler reminds us that according to Lacan binarity appears to be the irremovable basis of the Symbolic determined by our initial encounter with the prohibition of the Law [2. P. 54-55]. The original cause of binary logic could be also derived from Freudian clash between "pleasure principle" and "reality principle" and from resistance emerging between Fichtean the "I" and "non-I".

Why, even admitting the possible vainness of our efforts, do we still seek to exceed the limits of binarity? Though special investigation of the problem of binarity as such is not among the goals of the current study, we should briefly point at several aspects of this problem. Binarity is present in numerous polar oppositions that fill mythological consciousness of an archaic man as it was depicted by M. Eliade. Dual structures that C. Levi-Strauss discovered in both primitive thought and modern culture phenomena are the embodiment of binarity. How could the subject-object rationality be possible without binary logic? Could we bring order into reality of things without comparing ourselves and the world? Would we have an ability for purposeful-rational activity? Would people form deontological dimension if there was no binarity of what is and what ought to be? It is impossible to imagine culture, knowledge, social institutes, human being as such if we could take away the binarity.

Meanwhile, do we have a right to forget its other side? Binarity forms relations of domination and submission. Binarity is a basis for dividing people into "us" and "them". Through the logic of generalization binarity founds the reification of the Other when he is defined as an object in the line of similar objects. Humanism starts with exclusion of the object of specific type - human being - it starts with typization, with the typical but it should proceed further from typical to individual. And since any binarity is realized through typization we ask: is a real humanism as a relation to person in his or her personality and originality ever possible without transcending binarity?

An individual human being requires individual consideration, and, if otherwise, wouldn't it be only the being of some kind, particular class, or certain type? Yet, an individual wishing to be heard, seeking to be included into some structures of relations with us speaks of himself in terms of identity and very often primarily in terms of sex identity.

If there is only one sex/gender for everyone than there is no sex or gender at all. If sexes/genders are as many as subjects of identity than there is also no sex and no gender. Classness dissolves in universality as well in individuality. Without classification theory as always theory of general but not unique has nothing to lean. Where could the sex identity of a person emerge from if not from general categories of sexuality? Why do we need the problematization of sexual difference? We need it for differentiation. Differentiation in its own turn is required for identification. Why is sex/gender/sexuality identity so important? First, society marks the one who is not like others; when a person differs from dominant models, he wishes (if it's possible) to guarantee his right to be as he'd like without following 
repression or marginalization. The reality principle that manifests here in social restrictions for desirable pleasures and forms of relations demands correction of pleasure principle accordingly to certain prescribed types. It demands the protection of the right to practice that pleasure, and this protection usually needs defining of the self as a subject of the pleasure in terms of current discourse, uniting with those who are "similar" to you strengthens your position too. Second, it's likely that the question of sexual identity is getting more actualized as other types of identity cease to play the major role for a subject and lose their importance. For example, when there's an enemy at your gates and the world of yours and your dear people is brought to the brink of destruction, the identity derived from the orientation of your sexual desire hardly matters for you while the identity of the one who defends his home and his world comes to the foreground. In the existentially border situation, only existential identity makes sense. Similarly, those who stand by you wouldn't pay much attention to your gender, whether you are monogamous, polysexual, or another if they really care for the home you are defending together. The change in emphases as well as the rise of identities which are secondary to existential ones evidence that society has reached a certain level of stable well-being. The problem of social responsibility that obviously includes both responsibility of an individual before the society and responsibility of the society before an individual is put from a different angle.

We could reasonably conclude that the increasing of general well-being means that society develops new opportunities to take care of an individual, and, when the well-being of society decreases, an individual takes care for the "common home". But the reverse logic is also true. With the increase of adversity, society ought to be concerned about the life of an individual too, and, in the time of prosperity, an individual still retains the responsibility before the society. It depends on him whether the society will change to more humanitarian conditions and whether it will grasp the values of freedom and mutual respect. Should we in that case take the overcoming or at least the softening of binary oppositions in regard to sexual identity as "movement forward" - through liberating the field of possible projects of personal self-realization, establishing of new morality and so on - towards further humanization of society and social relations? Or is it just a phase in sinusoid of some cyclic dynamics (like the one that was described by Pitirim Sorokin)? Sexual identity is getting fixed as an answer to our demand for stability [7. P. 304]; achieving stability can permit some destabilization and deconstruction of our identities [18]. Yet, if the wheel goes round will barbarians come soon, will Rome fall together with all its exquisiteness and tolerance and will new ages of asceticism dawn alongside with the primacy of Eros exclusively in its "transformed", spiritual aspect? Doesn't the regression from postmodern pluralism to rational and pragmatic monism of modern times or even to irrational and dogmatic monism of pre-modern epoch seem quite possible to us now?

\section{CONCLUSION}

Whatever it could be, the establishing of sexual identity preserves binarity as logic for theory of sexuality. Is humanism beyond this logic achievable at all? If it is, it is most likely not in practices corresponding to theory of sex and identities built in accordance to the discourse of sexuality. Then, what practices they could possibly be? Solely in those when we address the Other in his or her uniqueness and exclusiveness. We need to admit that those practices (if they are indeed possible) should be prediscoursive, post-discoursive or supra-discoursive existential, aesthetical, non-instrumental, non-pragmatic and non-rationalizing (doesn't love belongs to them?). They demand constant effort to preserve the advertency towards the Other (the advertency that's usually present in the beginning of communication when the Other isn't defined and classified yet), constant attention to the Other, his or her dynamic singularity (with the own sex and sexual preferences, and so on), the singularity that is identical only to itself - and exactly to itself as it is in this particular moment. Perhaps, there's no way but by continuous looking at the Other in his or her unlikeness to you and to him or herself that you think you know (if else there come reification, habitualization, blurring of sight). Otherwise, you're caught by binarity which is mighty, comprehending, explaining, directing yet at the same time - dividing, conquering, pushing the Other aside and establishing him always as "the same as" any other object of a certain kind.

\section{REFERENCES}

[1] Cantor James M. Is Homosexuality a Paraphilia? The Evidence For and Against. // Arch Sex Behav, 2012, 41:237-247.

[2] Butler, Judith P. Gender trouble: feminism and the subversion of identity. - New York, 1990

[3] Callis, April S. Playing with Butler and Foucault: bisexuality and queer theory. // Journal of Bisexuality, 2009, 9:213-233.

[4] Tagirov, Philipp V. Substantiality of Desire and Transformations of Sexuality. // Bulletin of Peoples' Friendship University of Russia. Philosophy Series, 2015, № 1. P. 85-99.

[5] Mondimor, Francis M. A Natural History of Homosexuality. Paperback, 1996.

[6] Tagirov, Philipp V. "Another Eros": Institutional Changes and the Level of a Subject. // Humanities, Social, Economic and Social Sciences, 2015, № 6-1. P. 85-89.

[7] Erickson-Schroth Laura, Jennifer Mitchell. Queering queer theory, or why bisexuality matters. // Journal of Bisexuality, 2009, 9:297-315.

[8] Rudanovskaya Svetlana V. Subjects of Social Criticism: Between Reality and Desire. - Peoples' Friendship University of Russia, Publishing House, Moscow, 2005.

[9] Gooß, Ulrich. Concepts of bisexuality. // Journal of Bisexuality, 2008, 8:9-23.

[10] Halperin, David M. Forgetting Foucault: acts, identities, and the history of sexuality. // Representations, No 63 (Summer, 1998), pp.93-120.

[11] Tamsin Spargo. Foucault and Queer Theory. - Cambridge, 1999

[12] Foucault, Michel. The History of Sexuality. - Pantheon Books, New York, 1978.

[13] Halperin, David M. Thirteen ways of looking at a bisexual. // Journal of Bisexuality, 2009, 9:451-455.

[14] Kon, Igor S. Faces and Masks of Homosexual Love. Moonlight at the Dawn. - Moscow, 2003. 
[15] Berger, Peter L. and Luckmann, Thomas. The Social Construction of Reality. Penguin Books, 1991.

[16] Baudrillard, Jean. Seduction. - New World Perspectives, Montreal, 1990.

[17] Deleuze, Gilles and Guattari, Felix. Anti-Oedipus: Capitalism and Schizophrenia. University of Minnesota Press, Minneapolis, 2000.

[18] Bronzino, Lyubov Ju. and Vitkovskaya, Maria I. Gender Identity in the Context of Classic and Postmodern Feminism. // Sociological Journal, 2013, № 4 . 